\title{
Segmental Femoral Shaft Fracture: is a Particular Injury?
}

\author{
Rkiba Z*, Messoudi A, Rajaallah A, Rafaoui A, Garch A
}

Orthopedic Department P32, University Hospital Ibn Rochd, Faculty of Medicine \& Pharmacy of Casablanca, Morocco

DOI: $10.36347 /$ sasjs.2021.v07i01.009

| Received: 18.12.2020 | Accepted: 05.01.2021 | Published: 29.01.2021

*Corresponding author: Rkiba Zakaria

\section{Abstract}

Original Research Article

Introduction: Segmental fractures remain complex and particular injury. They result from high-energy trauma and are associated with a high rate of pseudoarthrosis. The aim of this work is to explain the difficulties of treating segmental femoral shaft fractures and to analyse the results of surgical treatment by intramedullary nailing (IMN). Patients and Methods: We studied a retrospective series of 20 cases of segmental femoral fractures over a seven-year period (20132019), treated with IMN and reviewed with an average of 30 months follow-up. Results: 20 patients presenting a segmental femoral fracture type 32-C2 according to AO. The average age of our patients was 33 years. 16 cases were victims of traffic accidents, we deplored in postoperative period one case of sural thrombophlebitis with good evolution. We had $80 \%$ union, in an average period of 30 weeks. Consolidation was more prolonged at the proximal focus than at the distal focus. We had four cases of aseptic pseudoarthrosis in the femur, successfully resumed by nailing and spongy grafting. Functionally, $15 \%$ of the cases presented a knee limitation and one of cases had rupture of ACL. Discussion: IMN proves to be the best means among the therapeutic arsenal in the surgical treatment of this particular entity but requires preoperative planning and technical requirements. Conclusion: This type of fracture must be considered as an entity apart from all diaphyseal fractures, both by the complexity of the fracture and the prolonged consolidation time. IMN, despite the difficulty of realization, remains a suitable therapeutic option.

Keywords: Fracture-segmental- femur - intramedullary nailing- outcome.

Copyright (C) 2021 The Author(s): This is an open-access article distributed under the terms of the Creative Commons Attribution 4.0 International License (CC BY-NC 4.0) which permits unrestricted use, distribution, and reproduction in any medium for non-commercial use provided the original author and source are credited.

\section{INTRODUCTION}

Segmental shaft fractures are defined as the occurrence of a two-level continuity solution isolating a complete cylindrical cortical segment, giving rise to two seating fracture lines of different type, displacement and evolution [1]. This type of fracture requires more specific therapeutic management and their osteosynthesis is difficult. These fractures are characterised by a high rate of delayed consolidation or pseudoarthrosis compared to monofocal fractures. These fractures are often the result of high-energy trauma and are usually accompanied by surrounding soft tissue injuries and distant injuries [2]. However, there is no consensus on the best operating technique and to cope with this uncertainty, intramedullary nailing remains a practical option provided that it meets a set of specifications. The aim of this work is to explain the difficulties in the management of segmental femoral shaft fractures and to analyze the results of surgical treatment by intramedullary nailing.

\section{PATIENTS AND METHODS}

The authors retrospectively reviewed 20 patients with segmental femoral fractures treated with locked intramedullary nailing in our department between January 2013 and December 2019. During the study period, we processed a total of 366 femoral fracture cases, with an overall rate of $4 \%$ for segmental femoral fractures. All fractures were classified according to the AO Orthopaedic and Trauma Association [3] and the Gustilo and Anderson classification for open fractures [4]. Segmental fractures of the femur were classified as type 32-C2. Interrogation and clinical examination looked for age, presence of diabetes, smoking, and mechanism, presence of vascular-nervous complications and associated trauma, and time to initial surgery. The average age of the patients was 33 years (17-42 years), the etiologies were dominated by traffic accidents with 16 cases (80\%), $45 \%$ of the cases were chronic smokers. We didn't have an open fracture. 17 patients were operated on locoregional anesthesia and three patients under general anaesthesia and all installed on orthopedic table. Fluoroscopic image was systematic. In principle, a minimally invasive approach to the intermediate fragment was performed allowing the intermediate fragment to be fixed with a forceps (figure 2). All the mountings were static. 


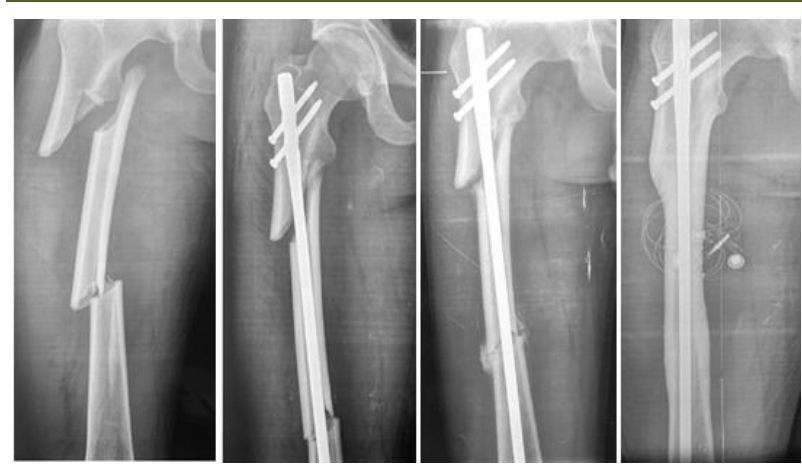

Fig-1: Segmental femoral fracture treated by IMN, fracture union after 30 weeks

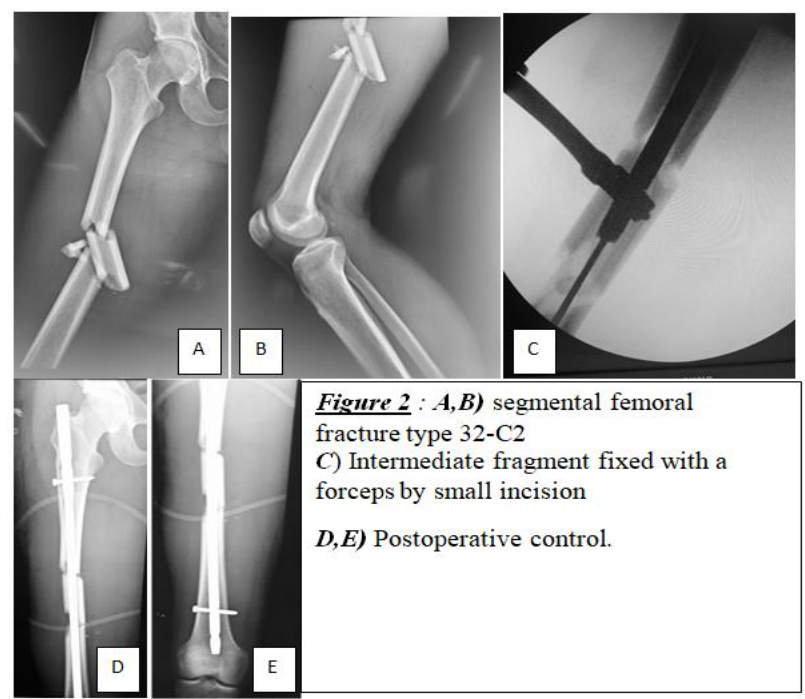

\section{RESULTS}

After an average decline of 30 months with an interval of (12-58 months). One case of sural thrombophlebitis with good evolution under medical treatment. We deplore the case of unraveling of the material at the level of the distal femoral focus by an insufficient length of the nail. The average consolidation period was 30 weeks. The consolidation period was 29 weeks and 26 weeks for the proximal and distal sites respectively. We found that consolidation was slightly longer in the proximal than in the distal focus but not significantly longer for the same bone segment. Four patients had aseptic pseudoarthrosis of the tibia. All patients with pseudarthrosis were reoperated by extracting nailing, reaming and nailing with bone graft in addition. We had no septic pseudoarthrosis or early infection. In terms of functional results, we had $15 \%$ of the cases presented a stiff knee with limitation of the flexion of which a patient had a anterior laxity with present Lachman. The MRI objectified a rupture of the ACL and hu benefited from a ligamentoplasty DIDT after union fracture with good clinical outcome.

\section{DISCUSSION}

Segmental fractures remain rare. Their occurrence is secondary to a high-energy trauma that may be associated with other local or distant injuries. There are few articles on the treatment of segmental fractures and the optimal method of fixation remains uncertain [5]. Some authors such as Boutin [6] and Decoulx [7] have considered these types of fractures to be a particular entity. Their management, after the elimination of a vital emergency, still remains a challenge for the orthopaedic surgeon. The analysis of the seat and the type of line of the fracture is essential. The surgical technique must meet precise specifications. It must allow a light but solid assembly, avoiding any loss of peripherality, reducing the risk of infection and allowing early rehabilitation. The elastic stable intramedullary nailing allows ensuring a closed focus, at the price of a difficult technique requiring an additional immobilization exposing to joint stiffness. Osteosynthesis by screwed plate exposes both foci with extensive periosteal dislocation. Mounting by plate bridging the intermediate focus requires a wide approach. Osteosynthesis by screwed plate does not allow for early support and exposes by its approach to the focus, to the evacuation of the haematoma and the loss of periosteum and to the risks of infection and pseudoarthrosis. Intramedullary nailing offers the advantages of a closed focus and the preservation of the peri-fracture haematoma, combined with static mounting, to meet the therapeutic requirements for this type of fracture. Despite the fact that reaming is a significant risk factor and causes rotation of the intermediate fragment, which leads to periosteal loss of blood flow and a reduction in vascular supply [8], it is therefore important to hold the fragment either with making a mini incision opposite the intermediate segment and fixing with a forceps during reaming. External fixation remains appropriate in the context of orthopaedic "damage control" or in severe or open trauma. Some authors recently like L.HUI et al. [9] recommend adding a mono-cortical plate by transforming the complex fracture into a simple fracture, and by neutralizing not only the shear forces but offering stability in rotation, they had encouraging results with a high union rate with an average of 18.9 weeks. The rate of pseudoarthrosis varies between 3 and $22 \%[10,11]$. In our series we had four cases of aseptic pseudoarthrosis (20\%). It is mainly the proximal focus which is the site of delayed consolidation or the appearance of pseudarthrosis. Unlike tibial fracture which are characterized by vascular precariousness (distal site, absence of clear muscle insertion), the delay in union of segmental femoral fracture is mainly a technical problem.

These fractures were always characterised by a prolonged consolidation time ranging from 15 to 43 weeks [12, 13-16]. These data are based on comparisons with historical data from the literature [12]. The mean healing time in our series was 30 weeks. The association with soft tissue injury and initial reduction also remain factors in delayed healing, but not specific to this type of fracture, as do other factors 
related to the patient such as smoking, diabetes or other co-morbidities.

\section{CONCLUSION}

Treatment by intramedullary nailing seems to be the treatment of choice for segmental fractures of the femur and provides good results, these fractures are peculiar and pose a challenge to orthopaedic surgeons, they require even more studies on surgical technique in order to establish a consensus for optimal management, and shorten the consolidation time and lower the rate of pseudoarthrosis which puts at stake the functional prognosis.

\section{Conflicts of interest}

The authors declare no conflict of interest.

\section{REFERENCES}

1. Woll TS, Duwelius PJ. The segmental tibial fracture. Clin Orthop Relat Res. 1992:204-7.

2. Wu CC, Shih CH. Segmental tibial shaft fractures treated with interlocking nailing. J Orthop Trauma. 1993; 7:468-472.

3. Marsh JL. "Fracture and dislocation classification compendium-2007: Orthopaedic trauma classification, data-base and outcome committee." J Orthop Trauma. 2007: S47-S50.

4. Gustilo RB, Mendoza RM, Williams DN. Problems in the management of type III (severe) open fractures: a new classification of type III open fractures. J Trauma. 1984;24:742-746.

5. Baker SP. The injury severity score (ISS) : A method for describing patients with multiple injuries and evaluating emergency care. J Trauma. 1974;14:187-96.

6. Boutin P. 25 cas de fractures bifocales de jambe. Rev Chir Orthop. 1956; 42: 647-663

7. DeCoulx P, Ducloux M, Dupont M. Les fractures bifocales de jambe: a propos de 30 cas. Acta Orthop Belg. 1963; 29: 628- 640
8. Arastu MH. "Does it really spin? Intra-medullary nailing of segmental tibial fractures-A cadaveric study." Injury. 2015; 46(4): 643-648.

9. Liu H, Wu J, Lin D, Lian K, Luo D. Results of combining intramedullary nailing and plate fixation for treating segmental femoral fractures. ANZ journal of surgery. 2019 Apr;89(4):325-8.

10. Anastopoulos G, Asimakopoulos A, Exarchou E, Pantazopoulos T. Closed interlocked nailing in comminuted and segmental femoral shaft fractures. The Journal of trauma. 1993 Nov;35(5):772-5.

11. Wu CC, Shih CH, Ueng WN, Chen YJ. Treatment of segmental femoral shaft fractures. Clinical orthopaedics and related research. 1993 Feb(287):224-30.

12. Teraa M, Blokhuis TJ, Tang L, Leenen LP. Segmental tibial fractures: an infrequent but demanding injury. Clinical Orthopaedics and Related Research®. 2013 Sep 1;471(9):2790-6.

13. Bonnevialle P, Cariven P, Bonnevialle N, Mansat P, Martinel V, Verhaeghe L, Mansat M. Segmental tibia fractures: a critical retrospective analysis of 49 cases. Revue de chirurgie orthopedique et reparatrice de l'appareil moteur. 2003 Sep;89(5):423-32.

14. Giannoudis PV, Hinsche AF, Cohen A, Macdonald DA, Matthews SJ, Smith RM. Segmental tibial fractures: an assessment of procedures in 27 cases. Injury. 2003 Oct 1;34(10):756-62.

15. Giotakis N, Panchani SK, Narayan B, Larkin JJ, Al Maskari S, Nayagam S. Segmental fractures of the tibia treated by circular external fixation. The Journal of bone and joint surgery. British volume. 2010 May;92(5):687-92.

16. Sarmiento A, Latta LL. Functional treatment of closed segmental fractures of the tibia. Acta Chir Orthop Traumatol Cech. 2008 Oct 1;75(5):325-1. 